\title{
Clinical Outcome of Infrapopliteal Angioplasty for Treatment of Chronic Lower Limb Ischemia
}

\author{
Seyed Rasool Mirsharifi ${ }^{1}$, Hossein Ghanaati ${ }^{2,3}$, Morteza Noparast ${ }^{1}$, Sara Farifteh ${ }^{1,{ }^{*}}$, Madjid Shakiba ${ }^{2}$ \\ and Parto Sabetrasekh ${ }^{2}$ \\ ${ }^{1}$ Department of General Surgery, Imam Khomeini Hospital, Tehran University of Medical Sciences, Tehran, Iran \\ ${ }^{2}$ Advanced Diagnostic and Interventional Radiology Research Center (ADIR), Tehran University of Medical Sciences, Tehran, Iran \\ ${ }^{3}$ Department of Radiology, Imam Khomeini Hospital, Tehran University of Medical Sciences, Tehran, Iran \\ Corresponding author: Department of General Surgery, Imam Khomeini Hospital, Tehran University of Medical Sciences, Tehran, Iran. Tel: +98-9133984859, Fax: \\ +98-2161191609, Email: sara.farifteh@gmail.com
}

Received 2016 August 21; Revised 2018 December 26; Accepted 2018 December 30

\begin{abstract}
Background: Chronic lower limb arterial stenosis is a condition that impairs the quality of life and could result in amputation. One of the major treatments is angioplasty to open the stenosis.

Objectives: We evaluated the midterm results of endovascular treatment of infra popliteal arterial disease as a primary intervention to reduce the level of ischemia in order to avoid major amputation.

Patients and Methods: Between March 2013 and April 2015, we collected all data of patients who underwent infrapopliteal angioplasty for chronic limb ischemia (CLI), (Rutherford category 4,5, or 6). The outcome as freedom from reintervention, limb salvage, improvement of signs and symptoms, and the overall survival was analyzed. We reviewed the results of angioplasty by anatomic characteristics of the lesion, transatlantic intersociety characteristics (TASC).

Results: Forty seven patients were enrolled in this study of whom 37 were male. Mean age was 67.2 years. Mean ankle brachial index (ABI) before and 6 months after percutaneous transluminal angioplasty (PTA) was $0.5 \pm 0.07$ and $0.68 \pm 0.12$, respectively (P $<0.01$ ) and an improved ABI of at least 0.1 was detected in $78 \%$ of the patients. In $97.2 \%$, initial technical success was obtained. Rest pain was completely resolved in $66.7 \%$ of the patients after the 3-month follow-up and $72.7 \%$ after the 6-month follow-up after the procedure. Complete or relative healing of chronic ulcer was seen in $69 \%$ and $92 \%$ of patients in the 3-and 6-month follow-up after the procedure, respectively. Restenosis occurred in four patients (8.5\%), major amputation in 19.1\% (9 patients) and the mortality rate was $25.1 \%$ (12 cases). Primary patency was finally estimated as $76.1 \%$.

Conclusions: PTA for infrapopliteal lesions in high-risk patients can reduce the risk of amputation with a lower mortality and morbidity.
\end{abstract}

Keywords: Infrapopliteal, Angioplasty, Limb Ischemia

\section{Background}

Chronic limb ischemia (CLI) is associated with high morbidity and mortality in such a way that if the medical and surgical treatment fails it will be associated with a high risk of amputation (1).

The effectiveness of peripheral bypass grafts and percutaneous transluminal angioplasty (PTA) in achieving limb salvage has been established (2). However, distal bypass surgery may be associated with significant morbidity and not all patients are suitable candidates for distal bypass surgery due to age, underlying disease, anatomic factors, and multiple and diffuse arterial stenosis (3).

In these patients, PTA has become an acceptable form of treatment for patients with infra inguinal arterial occlusive disease (1). With PTA, local anesthesia can be used, hospital stay is shorter, and morbidity and mortality rates may be lower, and it will not affect future possible surgical bypass (4). In contrast with femoropopliteal PTA, infrapopliteal or crural angioplasty (PTA) has been less frequently used and has produced more heterogeneous results, and it still remains controversial (5).

Recently, the bypass versus angioplasty in severe ischemia of the leg (BASIL) study indicated that if the anatomy is conducive for angioplasty, primary PTA might be an appropriate first therapy even if the patient is a good candidate for bypass (6). The outcomes of tibial PTA are difficult to predict from the existing literature. 


\section{Objectives}

The objective was to review the results of infrapopliteal angioplasty and classify the result of angioplasty by anatomic characteristics according to the TASC classification.

\section{Patients and Methods}

All patients who underwent primary infrapopliteal PTA between April 2013 and March 2015 due to CLI at our hospital were evaluated. Indication of PTA in these patients was severe chronic limb ischemia (Rutherford-Becker 4,5 , or 6 ) with compatible imaging data for significant involvement of infra popliteal arteries (stenosis $>50 \%$ ). Non-viable and gangrene limb, angioplasty for acute limb ischemia, history of surgical bypass in the affected limb and angioplasty for treatment of the occluded graft (vein or prosthetic) were exclusion criteria. Demographic, clinical, laboratory and technical data were recorded. Ankle brachial index (ABI) and computed tomography angiography (CTA) or magnetic resonance angiography (MRA) findings were collected. Evaluation of lesion anatomy was performed based on trans-atlantic inter-society consensus (TASC) classification and determined by examination of the procedure notes.

Prior to intervention, patients were pre-medicated with clopidogrel (Plavix®) and aspirin (ASA) and maintained on ASA $100 \mathrm{mg}$ per day after the procedure.

Selective angioplasty of the affected limb was performed under local anesthesia through the common femoral artery (CFA), preferably in the form of antegrade by sheet $5 \mathrm{~F}$ or $6 \mathrm{~F}$. Based on the patient's weight 3000 to 5000 IU heparin was injected as bolus IV dose. A diagnostic arteriogram was performed with the least amount of contrast agent and the stenosis was characterized by TASC classification and the best approach was selected. Then, the stenosis was passed with a hydrophilic guide wire (Boston scientific V18 and cordis SV5) and balloon angioplasty was performed by use of appropriate balloon size, usually 1.5 - $3 \mathrm{~mm}$ based on normal adjacent vessels diameter, while it is $4 \mathrm{~mm}$ for the tibio-peroneal trunk. Atmospheric pressure inside the balloon was kept at 4 - 12 for about $60 \mathrm{sec}$ onds, nearby stenosis. If there was an occlusion and inability to pass the guidewire, the sub-intimal plane was used for angioplasty. If there was concurrent femoropopliteal stenosis, angioplasty was performed if necessary. Control angiography was done to evaluate blood flow and technical success. The ultimate goal of angioplasty was to create at least one patent artery in the plantar arch of the leg.

All patients were planned to be followed up in 3, 6 and 12 months after angioplasty. Improvement of their clinical complaints including rest pain (based on visual analog score) and claudication was asked and recorded.
All patients were assessed regarding chronic ulcer and wound healing. Worsening was recorded compared to preangioplasty condition. ABI was measured and compared with the baseline data. Color Doppler sonography was performed six months after PTA and vascular status was checked.

Descriptive analysis was carried out for all independent variables and reported as average values and standard deviation for continuous variables and as percentages for the qualitatives. $T$ test was used for comparison of continuous variables, and chi-square analysis was used for comparison of categorical variables. Treatment outcome, primary patency and mortality rate was analyzed by KaplanMeier method. P value less than 0.05 were considered statistically significant. All findings were analyzed using SPSS ver. 18 (SPSS Inc. released 2009. PASW Statistics for Windows, Version 18.0. Chicago, IL).

\section{Results}

\subsection{Baseline Characteristics}

Totally 47 patients were assessed in the study. Mean age of the patients was $67.2 \pm 13$ years ( 34 - 87) and 37 were male (78.7\%). All of baseline characteristics and clinical findings are mentioned in Table 1 . The most frequent comorbid disease was diabetes seen in 39 patients (83\%). The most frequent medication among the patients was ASA (24, 51.1\%). In addition, the most frequent TASC classification was class C that was seen in 17 (36.2\%) of the patients. Then, class B was more common seen in 16 patients (34\%). Regarding clinical manifestations, claudication was seen in 35(74.5\%), chronic ulcer in 37 (78.7\%) and rest pain in 14 (29.8\%). Mean of ankle brachial index (ABI) before procedure was $0.5 \pm$ $0.07(0.4-0.7)$. All of the baseline characteristics and clinical findings are mentioned in Table 2.

\begin{tabular}{|c|c|}
\hline Term & Definition \\
\hline Initial technical success & $\begin{array}{l}\text { PTA resulting in less than } 30 \% \text { residual stenosis } \\
\text { with sufficient antegrade flow }\end{array}$ \\
\hline Primary clinical success & $\begin{array}{l}\text { Improvement of at least one clinical category in } \\
\text { the Rutherford classification or wound healing } \\
\text { in category } 5,6\end{array}$ \\
\hline Improved ABI & Increase in $\mathrm{ABI}$ of at least 0.1 \\
\hline Primary patency & $\begin{array}{l}\text { Persistent patency without any re-intervention } \\
\text { including angioplasty, surgical procedures } \\
\text { performed on treated lesion, or major } \\
\text { amputation }\end{array}$ \\
\hline Limb salvage & Prevention of major amputation \\
\hline Major amputation & $\begin{array}{l}\text { Limb loss below or above the knee level, while } \\
\text { minor amputation was defined as a } \\
\text { trans-metatarsal or more distal level } \\
\text { amputation of the lower extremity. }\end{array}$ \\
\hline
\end{tabular}




\begin{tabular}{|c|c|}
\hline Baseline and Clinical Data & Values $^{\mathrm{a}}$ \\
\hline \multicolumn{2}{|l|}{ Age, $y$} \\
\hline Mean $\pm S D$ & $67.2 \pm 13$ \\
\hline Range & $34-87$ \\
\hline \multicolumn{2}{|l|}{ Gender } \\
\hline Male & $37(78.7)$ \\
\hline Female & $10(21.3)$ \\
\hline \multicolumn{2}{|l|}{ Comorbid disease } \\
\hline Hypertension & $19(40.4)$ \\
\hline Diabetes mellitus & $39(83)$ \\
\hline Hyperlipidemia & $2(4.3)$ \\
\hline Ischemic heart disease & $17(36.2)$ \\
\hline \multicolumn{2}{|l|}{ Smoking } \\
\hline Smoker & $16(34)$ \\
\hline Ex-smoker & $21(44.7)$ \\
\hline Non smoker & $10(21.3)$ \\
\hline \multicolumn{2}{|l|}{ Medications } \\
\hline ASA & $13(27.7)$ \\
\hline Warfarin & $2(4.3)$ \\
\hline Statins & $2(4.3)$ \\
\hline ASA + statins & $7(14.9)$ \\
\hline ASA + clopidogrel & $4(8.5)$ \\
\hline No & $19(40.4)$ \\
\hline \multicolumn{2}{|l|}{ TASC classification } \\
\hline A & $4(8.5)$ \\
\hline B & $16(34)$ \\
\hline C & $17(36.2)$ \\
\hline $\mathrm{D}$ & $10(21.3)$ \\
\hline \multicolumn{2}{|l|}{ Clinical manifestation } \\
\hline Rest pain & $14(29.8)$ \\
\hline Claudication & $35(74.5)$ \\
\hline Chronic ulcer & $37(78.7)$ \\
\hline \multicolumn{2}{|l|}{ ABI before angioplasty } \\
\hline Mean $\pm S D$ & $0.5 \pm 0.07$ \\
\hline Range & $0.4-0.7$ \\
\hline
\end{tabular}

Abbreviations: ABI, ankle brachial index; ASA, aspirin; TASC, transatlantic intersociety characteristics; y, years

${ }^{a}$ Values are expressed as No. (\%) unless otherwise indicated.

\subsection{Procedure Data and Technical Success}

Technical success of performing the procedure was $100 \%$. All 47 patients underwent angiography via common femoral artery (CFA) and access method was antegrade in 41 (87.2\%). One technical failure due to diffuse atherosclerosis and unsuccessful placement of guide wire was reported. In 97.2\%, initial technical success was obtained.

The most frequent angioplasty location was anterior tibial artery (ATA) performed in 33 patients (70.2\%) and then the tibioperoneal trunk performed in 19 patients (40.4\%) (Table 3). Isolated ATA angioplasty was performed in $36 \%$ but concurrent multi vessel intervention was performed in $64 \%$. In six patients, concurrent femoropopliteal

\begin{tabular}{|cc|}
\hline Table 3. Angiography Characteristics Data Among Patients & \\
\hline Angiography Characteristics & No. $(\%)$ \\
\hline Access & $41(87.2)$ \\
\hline \multicolumn{1}{|l}{ Retrograde } & $6(12.8)$ \\
\hline Antegrade & \\
\hline Angioplasty location & $33(70.2)$ \\
\hline Anterior tibial artery & $18(38.3)$ \\
\hline Posterior tibial artery & $15(31.9)$ \\
\hline Peroneal artery & $19(40.4)$ \\
\hline Tibioperoneal trunk & $6(12.8)$ \\
\hline Concurrent femoropopliteal & \\
\hline Minor complication & $5(10.6)$ \\
\hline Hematoma & $1(2.1)$ \\
\hline Pseudoaneurysm & $2(4.3)$ \\
\hline Arterial spasm & \\
\hline
\end{tabular}

involvement was seen in whom angioplasty was done. There was no major complication during and after the procedure. The most frequent minor complication was hematoma seen in five patients (10.6\%). They did not need any intervention.

\subsection{Clinical Outcome and Follow up Data}

Mean follow up time was $9.7 \pm 6.6$ months (1-30). Mean ABI 6 months after the procedure was $0.68 \pm 0.12$ (0.4-0.9). Among the patients with data of ABI before and 6 months after the procedure, the mean improvement of $\mathrm{ABI}$ was 0.17 \pm 0.11 (0 - 0.5) (change from $0.51 \pm 0.08$ to $0.68 \pm 0.12$ ) (P $<0.001$ ). Improved ABI ( $>0.1$ ) was detected in $78 \%$ of patients (primary clinical success).

Among 14 patients with rest pain at the beginning of the study, for 12 patients we had data for evaluation of rest pain after 3 and 6 months. Among these patients, eight (66.7\%) reported complete improvement of rest pain and the others reported relative rest pain improvement (four patients, 33.3\%). Therefore, all patients reported improvement in rest pain 3 and 6 months after the procedure $(\mathrm{P}<$ 0.001). Pain improvement was statistically similar in different TASC classes and pain improvement was not different between two groups of TASC $[A, B]$ vs. [C,D] patients $(P=0.58)$. Clinical results of pain improvement after 6 months was similar to 3 months follow up data. Among 11 patients with pain improvement after 6 months, eight reported complete improvement (72.7\%) and three reported improvement in rest pain (27.3\%). Thus, all patients reported improvement after 6 months $(\mathrm{P}<0.001)$ and the pattern of improvement was not statistically different between TASC groups of $[A, B]$ vs. $[C, D]$ patients $(P=0.9)$ (Table 4).

Among 35 patients with claudication before angioplasty, the data of 32 were available after 3 months. Among them, 14 reported complete improvement (43.8\%) ( $\mathrm{P}<$ 


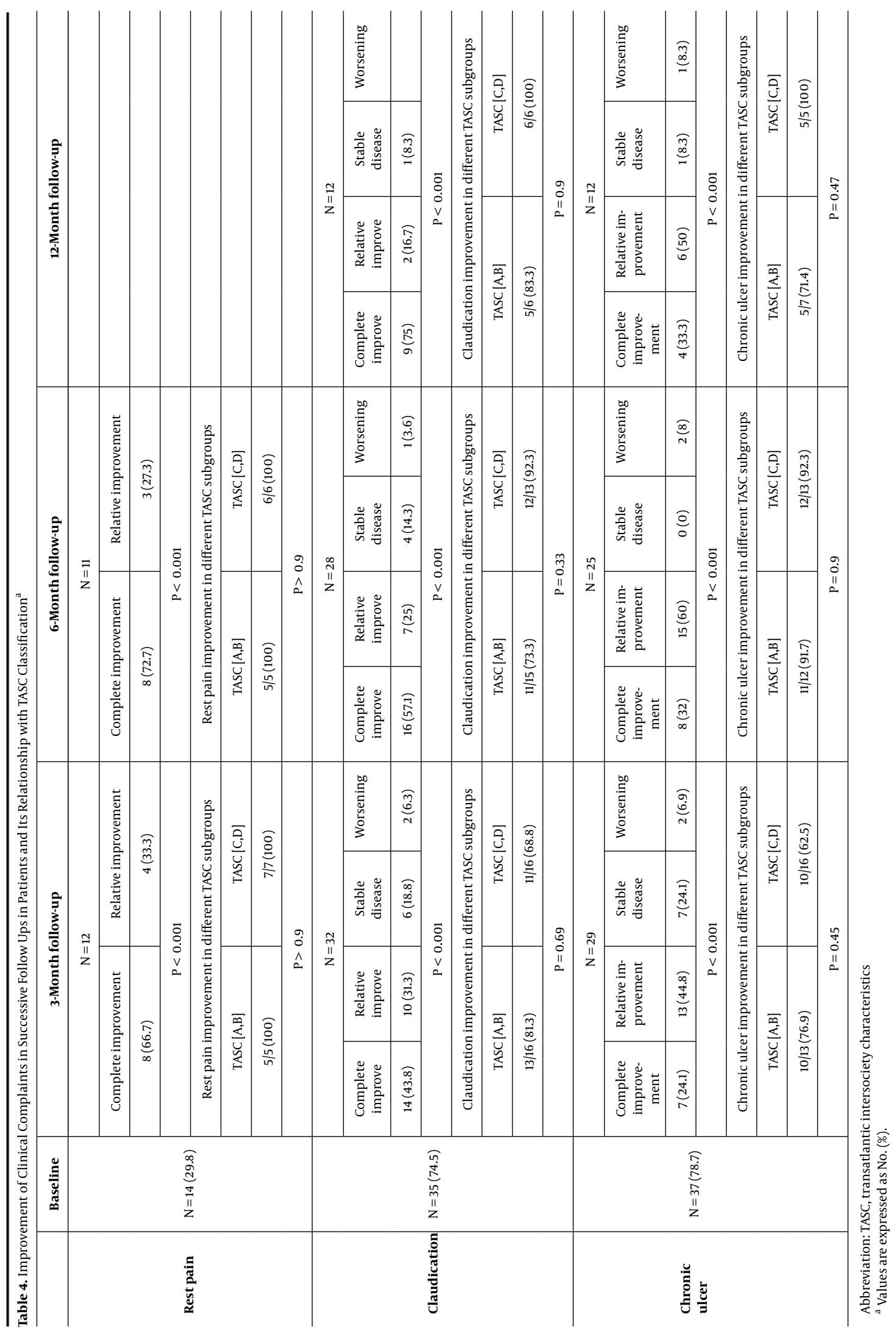


0.001 ) and 10 reported relative improvement (31.3\%). Thus, totally 24 patients experienced improvement in claudication $(\mathrm{P}<0.001)$. Among the remaining eight patients, six reported no change in their claudication (18.8\%) and only two patients (6.2\%) experienced worsening of claudication. Totally, 28 of these patients completed 6 month follow up; in which, 16 (57\%) reported complete and seven (25\%) reported relative improvement $(\mathrm{P}<0.001)$. Among 12 patients with one-year follow up, 11 reported improvement (91.7\%, nine complete, and two relative $)(\mathrm{P}<0.001)$. Claudication improvement was not statistically different among TASC $[A, B]$ group vs. TASC [C,D] group after 3, 6 and 12 months follow up (all Ps $>0.3$ ) (Table 4).

Among 37 patients with chronic ulcer, 29 completed 3 month follow up of whom seven (24.1\%) reported complete ulcer healing and 13 (44.8\%) experienced relative ulcer healing $[\mathrm{P}<0.02]$. Seven patients $(24.1 \%)$ showed no improvement in ulcer and two (6.9\%) showed deterioration in their ulcer. These figures were 8 (32\%), 15 (60\%) and two (8\%) for complete improvement, relative improvement and worsening of ulcer, respectively in 6 month follow up $[\mathrm{P}<0.001$ for improvement in 6 months] Again, frequency of ulcer improvement was not statistically different between TASC group of [A,B] vs. [C,D] in all follow up sessions [Ps > 0.45] (Table 4).

Restenosis occurred in four patients who underwent angioplasty and stent placement. We had major amputation in nine patients (19.1\%) that was above the knee in two patients. Mean amputation time was $2.5 \pm 2$ months after the procedure (range: 20 days-5 month). In two patients, amputations were performed in the first month after angioplasty and in one patient, acute ischemia and thrombosis of ATA occurred immediately after the procedure, that despite repeated angioplasty, amputation was unavoidable. No amputation occurred in TASC A patients, one amputation in TASC B patients (6.3\%), five in TASC C patients $(29.4 \%)$ and three in TASC D patients $(30 \%)(\mathrm{P}=$ 0.059 for comparing group $[A, B]$ vs. [C,D]). Mean amputation time in patients with TASC [C,D] was $2.7 \pm 2$ months. Comparing the survival pattern of amputation in two TASC groups of $[A, B]$ vs. $[C, D]$ using log rank test showed a statistical significant difference between these groups $(\mathrm{P}=0.04)$. Primary patency was finally estimated as 76.1.

Mortality rate was $25.5 \%$ ( 12 cases). The leading causes of death were myocardial infarction (MI) and sepsis. Each of them were responsible for death in three patients. Other causes were liver failure, renal failure and miscellaneous causes. Mean death time was $4.8 \pm 3.7$ months after the procedure (range: 1 - 12 months). Overall survival in one year was $74.5 \%$. Two related mortalities occurred due to ischemia deterioration, tissue loss, limb gangrene and sepsis as a consequence. Six mortalities occurred in patients who underwent amputation. No death occurred in TASC A patients, three in TASC B patients (18.8\%), four in TASC
C patients (23.5\%), and five in TASC D patients $(50 \%)(\mathrm{P}=$ 0.18 ). Mean mortality time in patients with TASC $[A, B]$ was $6.7 \pm 5.5$ months and it was $4.1 \pm 3$ months in TASC [C,D] group $(\mathrm{P}=0.7)$. Comparing survival pattern of death in two TASC groups of $[A, B]$ vs. [C,D] using log rank test showed no statistical significant difference between these groups $(\mathrm{P}=$ 0.04 ). Primary patency was finally estimated as $76.1 \%$.

\section{Discussion}

Infrapopliteal angioplasty has remained relatively underreported, partly due to early reports of limited technical success and poor outcomes $(6,7)$. Soder et al. (2), detailed their experience with infrapopliteal PTA for limb salvage in 72 limbs and noted an initial angiographic success rate of $61 \%$ in vessels with occlusions and 18-month primary patency and limb salvage rates of $48 \%$ and $80 \%$, respectively. Similarly, Vraux and Bertoncello (8) reported a technical success rate of $70 \%$ in 40 patients undergoing infra popliteal PTA for CLI with a 1-year primary patency rate of 58\%.These groups concluded that although infra popliteal PTA was feasible, the results did not justify a general application to patient care.

The application of smaller and more versatile coronary balloon and wire systems to the peripheral vascular circulation created new hope (3). As a multicenter, randomized controlled trial, BASIL (6) compares the outcome of a bypass-surgery-first strategy with a balloonangioplasty-first strategy in patients due to infra-inguinal disease associated with broadly similar outcomes in terms of amputation-free survival, and in the short-term, surgery is more expensive than angioplasty.

However, despite the failure of angioplasty compared with bypass surgery, for patients who are at high risk for surgery or have a shorter life expectancy (less than 1 - 2 years) angioplasty should be offered as the first approach (6) because it has lower mortality and morbidity and it does not affect possible future surgery if PTA fails. Angioplasty also seems to be a much less expensive option than surgery, at least in the short term. By contrast, in patients expected to live more than 2 years and who are relatively fit, surgery may be better option with lower risk of restenosis and also lower cost. Bosiers et al. detailed infrapopliteal PTA in 103 patients with CLI and reported a 1-year primary patency of $74.2 \%$ and limb salvage rate of $96.6 \%$, leading them to predict that primary PTA would become first-line therapy for CLI (9). In our study that used small balloon 1.5 - $2 \mathrm{~mm}$, primary patency and limb salvage was $76.1 \%$ and $80.1 \%$.

Although primary patency has been the indicator of technical success for arterial revascularization, but the real goal of therapy in patients with CLI is ulcer healing and limb salvage (10). The one year amputation-free survival (AFS) in patients with critical limb ischemia who re- 
ceived medical treatment was only $51 \%$, so the PTA for infra popliteal lesions in high risk patients can reduce the risk of amputation with lower mortality and morbidity. PTA of the infra-popliteal vessels can be performed safely, with a low periprocedural morbidity and mortality. Although primary patency rates are not as high as those reported in the vein bypass literature, excellent wound healing and limb salvage could be achieved with close follow-up and additional PTA if necessary. The lack of a control group for comparing bypass surgery with angiography is one of our study limitations. Medication consumption especially anti-platelet drugs could lead to selection bias. Although most patients were treated as part of an endovascular-first approach, some were referred for an endovascular procedure because of the lack of bypass target, lack of adequate vein conduit, and severe comorbidities precluding surgical bypass surgery that could affect the result.

In conclusion, angioplasty can be used as initial therapy for patients with chronic lower limb ischemia and perioperative complication will be less than surgery bypass. Although the likelihood of restenosis with PTA in infrapopliteal region is high but it could be acceptable when considered the affected patients with multiple comorbidities that make them too risky for surgery.

\section{Footnotes}

Authors' Contributions: Conception and design: Hossein Ghanaati, Seyed Rasool Mirsharifi, Morteza Noparast and Sara Farifteh; analysis and interpretation: Madjid Shakiba, Sara Farifteh and Parto Sabetrasekh; data collection: Sara Farifteh, Hossein Ghanaati and Parto Sabetrasekh; writing the article: Sara Farifteh; critical revision of the article: Seyed Rasool Mirsharifi, Hossein Ghanaati, and Parto Sabetrasekh; final approval of the article: Seyed Rasool Mirsharifi and Hossein Ghanaati; statistical analysis: Madjid Shakiba, Parto Sabetrasekh and Sara Farifteh; obtained funding: Sara Farifteh, Seyed Rasool Mirsharifi and Morteza Noparast; overall responsibility: Seyed Rasool Mirsharifi

Conflict of Interests: Authors declare no conflict of interests.
Ethical Approval: ir.tums.rec.1395.2271.

\section{References}

1. Parsons RE, Suggs WD, Lee JJ, Sanchez LA, Lyon RT, Veith FJ. Percutaneous transluminal angioplasty for the treatment of limb threatening ischemia: Do the results justify an attempt before bypass grafting? J Vasc Surg.1998;28(6):1066-71. doi:10.1016/S0741-5214(98)70033-3. [PubMed: 9845658].

2. Soder HK, Manninen HI, Jaakkola P, Matsi PJ, Rasanen HT, Kaukanen E, et al. Prospective trial of infrapopliteal artery balloon angioplasty for critical limb ischemia: Angiographic and clinical results. $J$ Vasc Interv Radiol. 2000;11(8):1021-31. doi: 10.1016/S1051-0443(07)613323. [PubMed: 10997465].

3. Tefera G, Hoch J, Turnipseed WD. Limb-salvage angioplasty in vascular surgery practice. J Vasc Surg. 2005;41(6):988-93. doi: 10.1016/j.jvs.2005.03.018. [PubMed: 15944598].

4. Feiring AJ, Wesolowski AA, Lade S. Primary stent-supported angioplasty for treatment of below-knee critical limb ischemia and severe claudication: Early and one-year outcomes. J Am Coll Cardiol. 2004;44(12):2307-14. doi: 10.1016/j.jacc.2004.09.037. [PubMed: 15607391].

5. Treiman GS, Treiman RL, Ichikawa L, Van Allan R. Should percutaneous transluminal angioplasty be recommended for treatment of infrageniculate popliteal artery or tibioperoneal trunk stenosis? Journal of Vascular Surgery. 1995;22(4):457-65. doi:10.1016/s0741-5214(95)70015-3.

6. Bradbury AW, Adam DJ, Bell J, Forbes JF, Fowkes FG, Gillespie I, et al. Bypass versus angioplasty in severe ischaemia of the leg (BASIL) trial: An intention-to-treat analysis of amputation-free and overall survival in patients randomized to a bypass surgery-first or a balloon angioplasty-first revascularization strategy.J Vasc Surg. 2010;51(5 Suppl):5S-17S. doi: 10.1016/j.jvs.2010.01.073. [PubMed: 20435258].

7. Romiti M, Albers M, Brochado-Neto FC, Durazzo AE, Pereira CA, De Luccia N. Meta-analysis of infrapopliteal angioplasty for chronic critical limb ischemia. J Vasc Surg. 2008;47(5):975-81. doi: 10.1016/j.jvs.2008.01.005. [PubMed: 18372148].

8. Vraux H, Bertoncello N. Subintimal angioplasty of tibial vessel occlusions in critical limb ischaemia: A good opportunity? Eur J Vasc Endovasc Surg. 2006;32(6):663-7. doi: 10.1016/j.ejvs.2006.06.006. [PubMed: 16935010].

9. Bosiers M, Hart JP, Deloose K, Verbist J, Peeters P. Endovascular therapy as the primary approach for limb salvage in patients with critical limb ischemia: Experience with 443 infrapopliteal procedures. Vascular. 2006;14(2):63-9. doi: 10.2310/6670.2006.00014. [PubMed: 16956473].

10. Vogel TR, Dombrovskiy VY, Carson JL, Graham AM. In-hospital and 30day outcomes after tibioperoneal interventions in the US Medicare population with critical limb ischemia. J Vasc Surg. 2011;54(1):109-15. doi: 10.1016/j.jvs.2010.12.055. [PubMed: 21397441]. 